\title{
Synthesis and Characterization of Organic Thin Film Using Atmospheric-Pressure Plasma Polymerization
}

\author{
Hidenobu Aizawa ${ }^{1}$, Yasutoshi Gokita ${ }^{1,2}$, Yasuo Yoshimi², \\ Tamao Hatta ${ }^{3}$, Subrayal M. Reddy ${ }^{4}$ and Shigeru Kurosawa ${ }^{1, *}$ \\ 'National Institute of Advanced Industrial Science and Technology (AIST), \\ 16-1 Onogawa, Tsukuba, Ibaraki 305-8569, Japan \\ ${ }^{2}$ Shibaura Institute of Technology, 3-7-5 Toyosu Koto-ku, Tokyo 135-8548, Japan \\ ${ }^{3}$ Japan International Research Center for Agricultural Sciences (JIRCAS), \\ 1-1 Ohwashi, Tsukuba Ibaraki 305-8686, Japan \\ ${ }^{4}$ University of Surrey, Guildford, Surrey GU2 7XH, UK
}

(Received March 23, 2010; accepted June 8, 2010)

Key words: atmospheric-pressure plasma, atmospheric plasma polymerization, organic thin film, biosensor, quartz crystal microbalance $(\mathrm{QCM})$

We developed a novel method of fabricating polymer film on a substrate at atmospheric pressure using atmospheric-pressure plasma polymerization (APPP) with a laboratory-made torch-type APPP apparatus. We used allylamine and acrylic acid as model monomers to optimize the polymerization conditions and evaluate the fabricated films. The APPP films were characterized by Fourier transform infrared (FT-IR) spectroscopy, contact angle measurement, atomic force microscopy (AFM), ellipsometry, X-ray photoelectron spectroscopy (XPS), deposition rate determination, and persistence measurement. Results showed that the properties of the APPP allylamine and acrylic acid films can be controlled by adjusting the polymerization parameter of ultrahighfrequency power.

\section{Introduction}

Analytical techniques using biosensors are useful for detecting specific molecules in medical diagnostics, environmental monitoring, and food inspection..$^{(1-5)}$ The techniques are remarkably simple, highly sensitive, selective, and fast. Biosensor sensitivity, selectivity, and stability strongly depend on the immobilization state of the receptor biomolecule on the biosensor biointerface. Therefore, to control biosensor performance, it is important to control the immobilized receptor biomolecule. ${ }^{(6-10)}$

*Corresponding author: e-mail: shigeru-kurosawa@aist.go.jp 
A plasma-polymerized thin film is a useful interface for immobilizing receptor biomolecules. Plasma polymers can be created by inducing the polymerization of monomer gas in a low-temperature thermal nonequilibrium state by high-frequency electric discharge. ${ }^{(11)}$ Polymers created by this method adhere firmly to the substrate because of their elevated bridge structure and are physically and chemically stable. Their structure and function can be controlled by controlling the polymerization conditions. ${ }^{(12-16)}$ However, their chemical composition, physical structure, and size are difficult to control, and they are difficult to form into films.

One method of forming plasma polymer into films is to use a mask. ${ }^{(17)}$ However, the mask must be removed before and after the film adheres to the substrate, which can be complicated.

An optimal method of forming plasma polymers into films would be to induce atmospheric-pressure plasma polymerization (APPP) in regioselective micrometer-scale plasma space. In general, sustaining plasma in small spaces is difficult owing to the loss of electrons on walls. Ito and Terashima have developed an ultrahigh frequency (UHF) source using thermoelectron support thermoelectron-enhanced micrometer-scale plasma (TEMP) to sustain stable micrometer-scale plasma generation. ${ }^{(18,19)}$ The micrometerscale plasma space is a very small, very high energy place, where plasma forms and radicals are efficiently generated. ${ }^{(20,21)}$ If the APPP reaction in this space can be made regioselective, a dry process of macromolecule polymerization could be attained on demand. ${ }^{(22,23)}$

Recently, analytical chemistry have introduced nanofabrication technology and miniaturization and integration sensors have been developed. The atmospheric pressure plasma used in this study can be used to prepare fine thin films. Fine thin films prepared with atmospheric pressure plasma can be used to prepare thin films with controlled nonspecific adsorption without losing their activity under the condition that receptors are immobilized. In this paper, we report on the successful formation of an APPP-generated polymer film from allylamine and acrylic acid monomers at low temperatures using a UHF power supply and torch-type APPP equipment.

\section{Materials and Methods}

Allylamine and acrylic acid monomers were of guaranteed grade, purchased from Wako Pure Chemical Industries Ltd. (Tokyo, Japan) and used without further purification. $10 \mathrm{mM}$ phosphate-buffered saline (PBS) buffer was prepared at $\mathrm{pH}$ 7.40. Ultrapure water $(18 \mathrm{M} \Omega \mathrm{cm})$ prepared with the Milli-Q system (Millipore Ltd., Tokyo, Japan) was used throughout all processes.

The torch-type APPP apparatus that we developed consists of an APPP torch and a UHF generator (438 MHz), a monomer reservoir, and two mass-flow controllers (Fig. 1). The APPP torch consists of a center tungsten electrode $(\phi 0.10 \mathrm{~mm}$ diameter $)$ set in a ceramic tube ( $\phi 0.5 \mathrm{~mm}$ internal diameter, $\phi 1.0 \mathrm{~mm}$ external diameter) inside a quartz tube ( $\phi 1.5 \mathrm{~mm}$ internal diameter, $\phi 3.0 \mathrm{~mm}$ external diameter) along the same axis. A coiled tungsten electrode is positioned outside the quartz tube. The center electrode is connected to a UHF power source, and the coiled electrode is grounded. Helium gas 


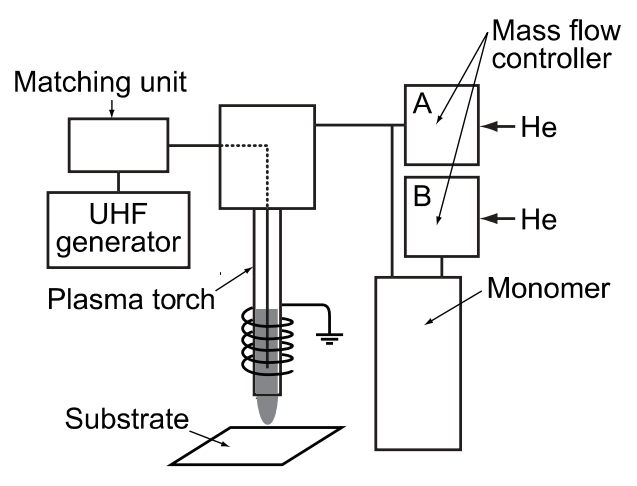

Fig. 1. Schematic diagram of the APPP equipment.

is passed between the ceramic and quartz tubes, inducing APPP in the limited space between them. Evaporated allylamine and acrylic acid monomer are supplied by flowing helium gas in the monomer reservoir of the APPP equipment. Both monomers were polymerized in this apparatus at UHF powers of 2,4 , and $6 \mathrm{~W}$ on each substrate under a direct plasma torch to form their respective films. The length and diameter of APP were $20 \times 1 \mathrm{~mm}^{2}$, respectively. Polymerization conditions are listed in Table 1.(25)

The FT-IR spectra of the generated films were obtained using a FTIR-610 (Jasco, Inc., Tokyo, Japan) at a resolution of $2 \mathrm{~cm}^{-1}$, while the instrument was purged with nitrogen gas. Each spectrum was averaged over 16 scans.

A contact angle meter (model CA-D, Kyowa Interface Science Co., Ltd., Saitama, Japan) measured contact angles of water on APPP films deposited on a coverglass $\left(18 \times 18 \times 0.12 \mathrm{~mm}^{3}\right.$, Matsunami Glass Ind., Ltd., Osaka, Japan). The contact angle was measured by the advanced angle method, carried out at $25 \pm 0.1^{\circ} \mathrm{C}$. A micropipette was used to add $10 \mu \mathrm{L}$ of ultrapure water.

To determine the surface topography and surface roughness of the APPP film, atomic force microscopy (AFM) was used. AFM topographic images and root mean square (rms) roughness were obtained at room temperature, using a MultiMode ${ }^{\circledR}$ AFM with a NanoScope ${ }^{\circledR}$ IIIa Ver. 5.30 controller (Digital Instruments, Veeco Metrology Group, Santa Barbara, CA). Film thickness was measured using ellipsometry (M540, Jasco, Inc., Tokyo, Japan). Film thickness was calculated from the ellipsometric parameters ( $\Delta$ and $\Psi$ ) using spectra manager and analysis software (Jasco, Inc.). The XPS profiles of the generated films were obtained using ESCA300 (VG Scienta AB, Sweden). The films were coated on a Si substrate before measurement. Peak separation was carried out after $\mathrm{C} 1 \mathrm{~s}, \mathrm{~N} 1 \mathrm{~s}$, and $\mathrm{O} 1 \mathrm{~s}$ were measured under the following conditions: source $=\mathrm{AlK} \alpha(1486.6$ $\mathrm{eV}$ ) X-rays, take-off angle $=90^{\circ}$, power $=1 \mathrm{~kW}$, resolution $=0.47 \mathrm{eV}$, pressure $=5 \times 10^{-7} \mathrm{~Pa}$. The silicon ( $\mathrm{Si}$ ) substrate (Optical flat polished and $0.1 \%$ boron-doped: $7 \times 7 \times 0.5 \mathrm{~mm}^{3}$ ) used for AFM, ellipsometry, and XPS were purchased from SUMCO Corporation (Tokyo, Japan).

APPP film thickness was measured using a quartz crystal microbalance (QCM) with gold electrodes on both surfaces (AT-cut $9 \mathrm{MHz}: 8 \times 8 \times 0.186 \mathrm{~mm}^{3}$ ), which was purchased 
Table 1

Atmospheric-pressure plasma polymerization conditions.

\begin{tabular}{lrc}
\hline & Allylamine & Acrylic acid \\
\hline Plasma He gas flow rate $\left(\mathrm{mL} \cdot \mathrm{min}^{-1}\right)$ & 190 & 100 \\
Monomer He gas flow rate $\left(\mathrm{mL} \cdot \mathrm{min}^{-1}\right)$ & 10 & 400 \\
Monomer temperature $\left({ }^{\circ} \mathrm{C}\right)$ & 5 & 30 \\
Polymerization time $(\mathrm{min})$ & 1 & 2 \\
\hline
\end{tabular}

UHF power: 2, 4, $6(\mathrm{~W})$

from Nihon Dempa Kogyo Co., Ltd. (Tokyo, Japan). The apparatus and procedure for determining mass loading were described previously. The film was deposited on one side of the QCM. A universal counter with data stored in a microcomputer was used to measure QCM oscillation frequency. All QCM measurements were performed at $20 \pm 2^{\circ} \mathrm{C}$. The weight of the film was determined from the difference between the frequencies measured before and after film deposition on the QCM, using the relationship $1 \mathrm{~Hz}=1 \mathrm{ng}$.

Persistence was measured by immersing the film-coated QCM electrodes in $\mathrm{pH}$ 7.40 PBS solution, shaking in solution at a rate of $0.5 \mathrm{~min}^{-1}$ for $12 \mathrm{~h}$, washing with pure water, drying with nitrogen gas for $12 \mathrm{~h}$, and measuring QCM oscillating frequency. The weight of the film remaining on the QCM was determined from the difference between the oscillating frequencies measured before and after immersion.

\section{Results and Discussion}

\subsection{FT-IR analyses}

Figure 2(a) shows the FT-IR spectra of the allylamine monomer and APPP allylamine film. Adsorption peaks are assigned as follows: A (N-H stretching, $\left.3360 \mathrm{~cm}^{-1}\right)$ and $\mathrm{B}(\mathrm{N}-\mathrm{H}$ deformation, $1630 \mathrm{~cm}^{-1}$ ). The peak at $2300 \mathrm{~cm}^{-1}$ is assigned to a nitrile group. The film clearly contains immobilized amino-group receptor biomolecules.

Figure 2(b) shows the FT-IR spectra of acrylic acid monomer and APPP acrylic acid film. Adsorption peaks are assigned as follows: $\mathrm{D}\left(\mathrm{C}=\mathrm{O}\right.$ stretching, $1720 \mathrm{~cm}^{-1}$, considered to be a carboxyl group of monomer origin), E (C-O-H plane deformation, $\left.1420 \mathrm{~cm}^{-1}\right)$, and F $\left(\mathrm{C}-\mathrm{O}\right.$ stretching, $\left.1200 \mathrm{~cm}^{-1}\right)$. Polyacrylic acid, which has a carboxyl group required for the immobilization of receptor biomolecules, also appears in the spectrum of the film polymerized at each UHF power. The carboxyl group clearly originates from the acrylic acid monomer.

\subsection{Contact-angle measurements}

Figure 3 indicates the measured contact angles between the water and the film. The angles are approximately the same for the two types of film and increase with increasing UHF power applied during polymerization. Increasing UHF power increases plasma density, and, therefore, increases the numbers of electrons and radicals related to monomer polymerization as the decomposition of the hydrophilic amino or carboxyl groups in the monomers progresses. 

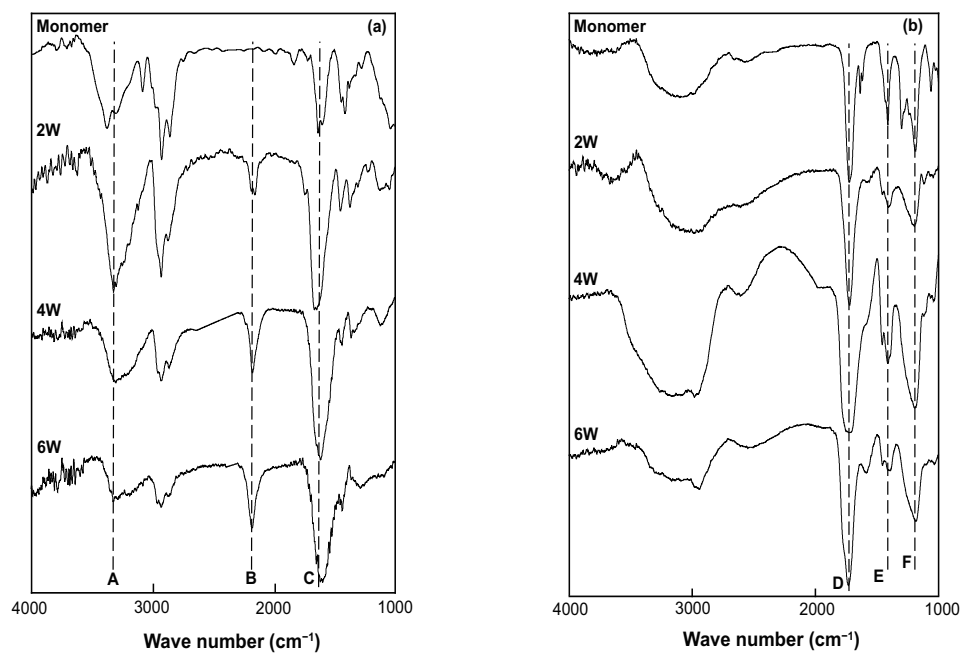

Fig. 2. FT-IR spectra of the monomers and their associated APPP films polymerized at different UHF powers: (a) allylamine; (b) acrylic acid.

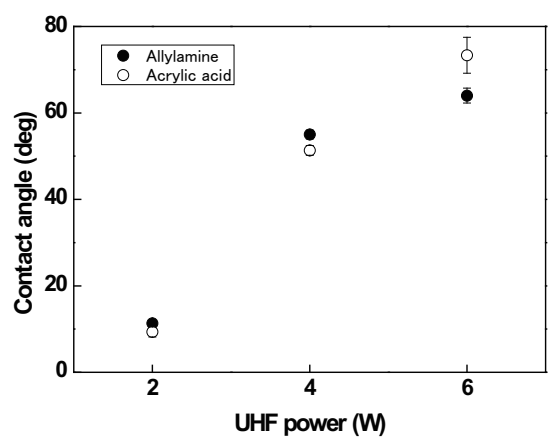

Fig. 3. Contact angles of water with respect to the surface of APPP allylamine and acrylic acid films as functions of UHF power applied during polymerization.

\subsection{AFM and ellipsometry analyses}

Figure 4 shows the tapping-mode AFM images that yielded information on the surface features of the APPP allylamine and acrylic acid films. The rms roughnesses and thicknesses of APPP allylamine and acrylic acid films are shown in Table 2. The APPP allylamine and acrylic acid films that polymerized at outputs of 4 and $6 \mathrm{~W}$ on the $\mathrm{Si}$ substrate showed smooth surfaces. On the other hand, the APPP allylamine and acrylic acid films that polymerized at $2 \mathrm{~W}$ showed a rough surface, and a film with a large rms was formed. Progress of film formation is considered to be the reason why the substrate face of the defective polymer contains monomers and oligomers. 

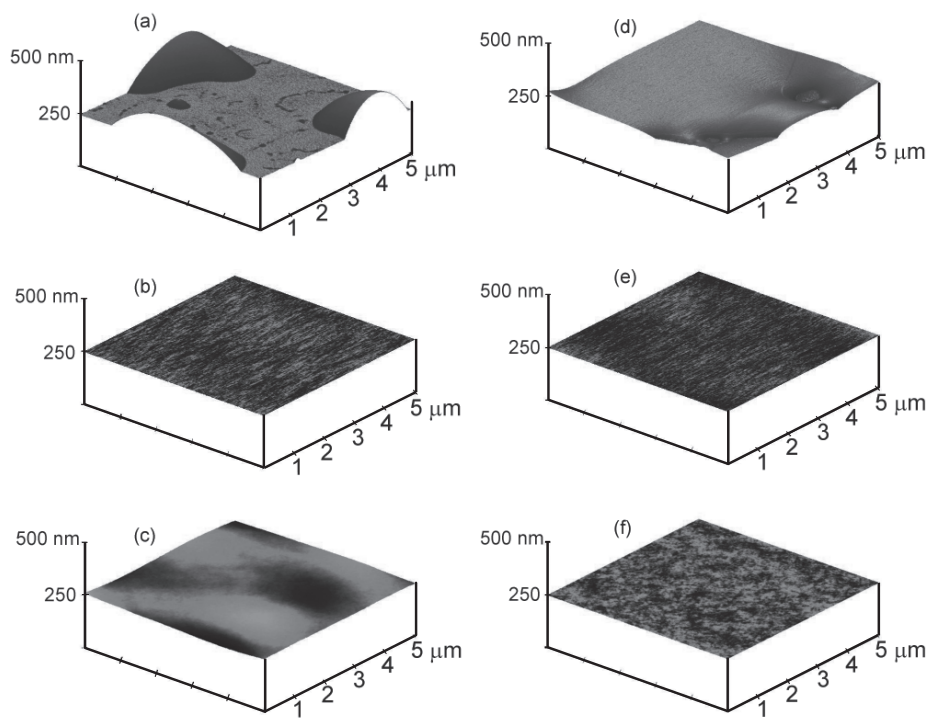

Fig. 4. AFM images of APPP-allylamine films at (a) $2 \mathrm{~W}$, (b) $4 \mathrm{~W}$, and (c) $6 \mathrm{~W}$, and APPP-acrylic acid films at (d) $2 \mathrm{~W}$, (e) $4 \mathrm{~W}$, and (f) $6 \mathrm{~W}$.

Table 2

Surface roughnesses and ellipsometric film thicknesses of APPP-allylamine and acrylic acid films.

\begin{tabular}{lccc}
\hline Monomer & Power $(\mathrm{W})$ & $\mathrm{rms}(\mathrm{nm})$ & Film thickness $(\mathrm{nm})$ \\
\hline \multirow{3}{*}{ Allylamine } & 2 & 72.22 & 180.0 \\
& 4 & 0.26 & 63.45 \\
& 6 & 5.71 & 33.59 \\
\hline \multirow{3}{*}{ Acrylic acid } & 2 & 16.06 & 437.4 \\
& 4 & 0.25 & 28.93 \\
& 6 & 0.30 & 70.0 \\
\hline
\end{tabular}

The thicknesses of the APPP allylamine and acrylic acid films measured using ellipsometry were small when the power of polymerization was large. The thickness of the film prepared at the power $2 \mathrm{~W}$ was larger than the film prepared at the powers 4 and $6 \mathrm{~W}$. From the result obtained by AFM, the thin film surface prepared at $2 \mathrm{~W}$ is rougher than the films prepared at 4 and $6 \mathrm{~W}$. The rough surface of the film affected the parameters $(\Delta$ and $\Psi$ ) used for computing film thickness.

\subsection{XPS analyses}

XPS peak separation was carried out after $\mathrm{C} 1 \mathrm{~s}, \mathrm{~N} 1 \mathrm{~s}$, and O1s were measured. A peak near $285 \mathrm{eV}$ is assigned to $\mathrm{CH}$ and $\mathrm{CH}_{2}$ of the polymerization film. ${ }^{(26)}$

The atomic percentages and results of the C1s peak fitting analysis of the APPP allylamine and acrylic acid films are shown in Table 3. For the APPP-generated allylamine film, with increasing UHF power applied during polymerization, the carbon 
Table 3

XPS analysis results of the derivatized APPP-allylamine and acrylic acid films.

\begin{tabular}{|c|c|c|c|c|c|c|c|c|c|}
\hline \multirow[b]{2}{*}{ Monomer } & \multirow[b]{2}{*}{ Power $(\mathrm{W})$} & \multicolumn{3}{|c|}{ Atomic percentage $(\%)$} & \multicolumn{5}{|c|}{$\mathrm{C} 1 \mathrm{~s}$ peak fitting analysis result (\%) } \\
\hline & & $\mathrm{C}$ & $\mathrm{N}$ & $\mathrm{O}$ & $\mathrm{CH}_{2}$ & $\mathrm{CH}$ & $\mathrm{C}-\mathrm{N}$ & $\mathrm{C}-\mathrm{O}$ & $\mathrm{C}=\mathrm{O}$ \\
\hline \multirow{3}{*}{ Allylamine } & 2 & 77 & 21 & 9 & 56 & - & 28 & 15 & - \\
\hline & 4 & 71 & 20 & 9 & 60 & - & 27 & 12 & - \\
\hline & 6 & 77 & 18 & 9 & 67 & - & 20 & 11 & - \\
\hline \multirow{3}{*}{ Acrylic acid } & 2 & 61 & - & 39 & 39 & 35 & - & - & 25 \\
\hline & 4 & 65 & - & 35 & 49 & 27 & - & - & 23 \\
\hline & 6 & 73 & - & 27 & 64 & 20 & - & - & 15 \\
\hline
\end{tabular}

concentration increases, and to approximately the same extent, both nitrogen and oxygen concentrations decrease. The $\mathrm{C}-\mathrm{N}$ carbon concentration decreases relative to the total carbon concentration in the film. Thus, the concentration of amino groups is shown to decrease, owing to decomposition, with increasing UHF power applied during polymerization.

For the APPP acrylic acid film, with increasing UHF power applied during polymerization, the carbon concentration increases and, to approximately the same extent, the oxygen concentration decreases. The concentration of $\mathrm{COOH}$ carbon decreases relative to the total carbon concentration in the film. Thus, the concentration of carboxyl groups is shown to decrease with increasing UHF power applied during polymerization.

\subsection{Film thickness and persistence}

Figure 5 shows the film thicknesses of the APPP allylamine and acrylic acid films. For both types of film, with increasing UHF power applied during polymerization, the film thickness decreases. Two deposition processes simultaneously contribute to film formation on the substrate: gas-phase space polymerization and solid-surface polymerization. During gas-phase space polymerization, the monomer polymerizes in the gas phase, then adsorbs onto the substrate to form a thin film. During solid-surface polymerization, the monomer reacts through electron and radical attack, at a rate that decreases as the substrate temperature increases, presumably owing to decreased rate of monomer adsorption. Increasing the UHF power clearly increases substrate temperature, and, therefore, with increasing UHF power, the extent of participation of solidsurface polymerization decreases until eventually only gas-phase space polymerization participates in film formation. Thus, the increasing UHF power applied during polymerization causes film formation to progress both more slowly and increasingly using gas-phase space polymerization.

Figure 6 shows the persistence of the two types of film to immersion in buffer solution. Films polymerized at a UHF power $<4 \mathrm{~W}$ decrease in weight with immersion, clearly due to exfoliation. Films polymerized at higher UHF powers do not exhibit this behavior. Presumably, at a UHF power $<4 \mathrm{~W}$, the plasma density is too low to enable the formation of good bridge structures, but at UHF powers of $\geq 4 \mathrm{~W}$, it is sufficient to do so. 


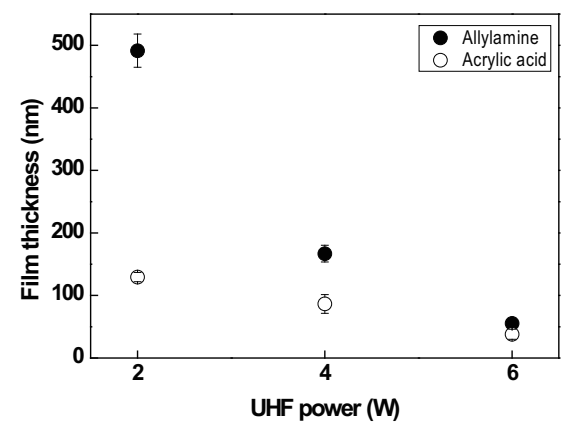

Fig. 5. Film thicknesses of allylamine and acrylic acid films on QCM as functions of UHF power applied during polymerization.
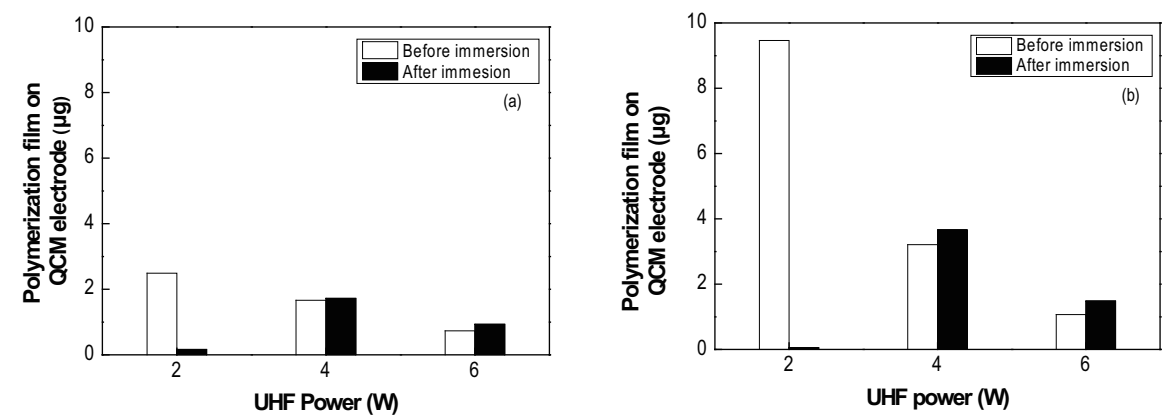

Fig. 6. Persistence in PBS buffer solution of APPP films polymerized at different UHF powers: (a) allylamine; (b) acrylic acid.

\section{Conclusions}

We fabricated polymer films by APPP and characterized the films by FT-IR, contact angle, XPS, AFM, ellipsometry and persistence. With increasing UHF power applied during polymerization, the concentration of functional groups in the film that originate from monomers decreases. For the films polymerized at a low power, the angle of contact with the film is small; as power increases, the contact angle changes from hydrophilic to hydrophobic, because the membranous hydrocarbon concentration increases. When immersed in PBS buffer, the films that polymerized at low powers display a significantly lower persistence than those that polymerized at high powers. These results suggest that APPP at UHF powers $\geq 4 \mathrm{~W}$ is optimal for fabricating polymer films that can immobilize receptor biomolecules.

\section{Acknowledgments}

This work was financially supported in part by Grants-in-Aid for Scientific Research on Priority Areas (Nos. 16040217 and 18030019) from Ministry of Education, Culture, 
Sports, Science and Technology (MEXT). Part of this work was conducted at the NanoProcessing Facility, supported by IBEC Innovation Platform, AIST.

\section{References}

1 E. Mallat, D. Barcelo, C. Barzen, G. Gauglitz and R. Abuknesha: Trends Anal. Chem. 20 (2001) 124.

2 P. B. Luppa, L. J. Sokoll and D. W. Chan: Clin. Chim. Acta 314 (2001) 1.

3 K. A. Marx: Biomacromol. 4 (2003) 1099.

4 B. Adhikari and S. Majumdar: Prog. Polym. Sci. 29 (2004) 699.

5 J. Castillo, S. Gáspár, S. Leth, M. Niculescu, A. Mortari, I. Bontidean, V. Soukharev, S. A. Dorneanu, A. D. Ryabov and E. Csöregi: Sens. Actuators, B 102 (2004) 179.

6 S. Kurosawa, M. Nakamura, J. W. Park, H. Aizawa, K. Yamada and M. Hirata: Biosens. Bioelectron. 20 (2004) 1134.

7 S. Kurosawa, H. Aizawa, Z. A. Talib, B. Atthoff and J. Hilborn: Biosens. Bioelectron. 20 (2004) 1165.

8 S. Kurosawa, H. Aizawa and J. W. Park: Analyst 130 (2005) 1495.

9 J. W. Park, S. Kurosawa, H. Aizawa, Y. Goda, M. Takai and K. Ishihara: Analyst 131 (2006) 155.

10 S. Kurosawa, J. W. Park, H. Aizawa, S. Wakida, H. Tao and K. Ishihara: Biosens. Bioelectron. 22 (2006) 473.

11 H. Yasuda: Plasma Polymerization (Academic Press, New York, 1985) Chaps. 1, 2 , and 6.

12 R. Nakamura, H. Muguruma, K. Ikebukuro, S. Sasaki, R. Nagata, I. Karube and H. Pedersen: Anal. Chem. 69 (1997) 4649.

13 Z. Wu, Y. Yan, G. Shen and R. Yu: Anal. Chim. Acta 412 (2000) 29.

14 S. Kurosawa, H. Miura, H. Takahashi, J. W. Park, H. Aizawa, K. Noda, K. Yamada and M. Hirata: Sens. Actuators, B 108 (2005) 558.

15 H. Muguruma: Trends Anal. Chem. 26 (2007) 433.

16 S. Mutlu, D. Çökeliler, A. Shard, H. Goktas, B. Ozansoy and M. Mutlu: Thin Solid Films 516 (2008) 1249 .

17 G. Kampfrath and R. Hinsche: Anal. Lett. 22 (1989) 2423.

18 T. Ito and K. Terashima: Appl. Phys. Lett. 80 (2002) 2648.

19 T. Ito, H. Nishiyama, K. Terashima, K. Sugimoto, H. Yoshikawa, H. Takahashi and T. Sakurai: J. Phys. D 37 (2004) 445.

20 S. Kurosawa, H. Harigae, J. W. Park, H. Aizawa, H. Suzuki and K. Terashima: J. Photopolym. Sci. Technol. 18 (2005) 273.

21 H. Harigae, H. Aizawa, S. Kurosawa, K. Terashima and H. Suzuki: Proc. ICRP-6/SPP-23 (2006) 335 .

22 S. Kurosawa, T. Hirokawa, K. Kashima, H. Aizawa, D. S. Han, Y. Yoshimi, Y. Okada, K. Yase, J. Miyake, M. Yoshimoto and J. Hilborn: Thin Solid Films 374 (2000) 262.

22 S. Kurosawa, B. Atthoff, H. Aizawa and J. Hilborn: Thin Solid Films 457 (2004) 26.

24 S. Kurosawa, B. G. Choi, J. W. Park, H. Aizawa, K. B. Shim and K. Yamamoto: Thin Solid Films 506 (2006) 176.

25 H. Harigae: Applied of Biosensor Using Atmospheric-Pressure Plasma Polymerization, Master thesis, University of Tsukuba, Ibaraki, Japan (2006).

26 G. Beamson and D. Briggs: High-Resolution XPS of Organic Polymers. The Scienta ESCA 300 Database (Wiley, U.K., 1992). 